\title{
Korelasi Hasil UKG SMA Tahun 2015 dengan Hasil UN Matematika SMA Tahun 2016 Daerah Istimewa Yogyakarta
}

\author{
Moch. Sukardjo ${ }^{1}$ \\ Lipur Sugiyanta ${ }^{2}$
}

\begin{abstract}
This research was aimed: (1) calculate the competence of mathematics teachers in 2015 in DIY, (2) calculate the average score of Mathematics UN of 2016, (3) to find out the correlation between mathematics teacher learning result 2015 at Matematika 2016 UN Result used is a quantitative descriptive with correlation formulation. Secondary data comes from the 2015 teacher competence test results from the Directorate General of GTK, Ministry of Education and Culture and UN 2016 produces data for the Center for Assessment of Education, Research and Development Agency, Ministry of Education and Culture. The population of all teachers the material attends UKG in 2015 and all 12th graders attending UN in 2016 and using saturated samples. Regression analysis shows that the value of mathematics mathematics 2015 does not affect the achievement of UN Mathematics 2016. Only 0.03\% Mathematics UN 2016 is determined by the value of Mathematics UKG 2015. These results indicate that the Mathematics UKG in 2015 has not impacted the increase in UN Mathematics in 2016.
\end{abstract}

Keywords: UKG 2015 SMA, UN 2016 SMA, Special Region of Yogyakarta, correlation, Mathematics

\begin{abstract}
Abstrak: Penelitian ini bertujuan untuk: (1) menghitung kompetensi guru mata pelajaran Matematika tahun 2015 di DIY, (2) menghitung rata-rata nilai UN Matematika tahun 2016, (3) menentukan korelasi antara hasil kompetensi guru Matematika tahun 2015 terhadap hasil UN Matematika tahun 2016. Metode yang digunakan adalah deskriptif kuantitatif dengan rumusan korelasi. Data sekunder berasal dari hasil ujian kompetensi guru tahun 2015 Dirjen GTK, Kementerian Pendidikan dan Kebudayaan dan data hasil UN tahun 2016 Pusat Penilaian Pendidikan, Badan Penelitian dan Pengembangan, Kementerian Pendidikan dan Kebudayaan. Populasi seluruh guru Matermatika yang mengikuti UKG tahun 2015 dan seluruh siswa SMA kelas 12 yang mengikuti UN tahun 2016 dan menggunakan sampel jenuh. Analisis regresi menunjukan bahwa nilai UKG Matematika 2015 tidak mempengaruhi perolehan nilai UN Matematika 2016. Hanya 0,03\% nilai UN Matematika 2016 yang ditentukan oleh nilai UKG Matematika 2015. Hasil tersebut menunjukkan bahwa UKG Matematika tahun 2015 belum memiliki dampak terhadap peningkatan UN Matematika pada tahun 2016.
\end{abstract}

Kata Kunci: UKG 2015 SMA, UN 2016 SMA, Daerah Istimewa Yogyakarta, korelasi, Matematika

\section{PENDAHULUAN}

Syarat utama untuk menjadi pendidik yang profesional, guru harus memiliki latar belakang pendidikan yang sesuai dengan mata pelajaran yang diampu, sedangkan untuk memenuhi persyaratan kompetensi, guru harus dapat membuktikan kemampuan kompetensi tersebut dengan sertifikat pendidik yang diperoleh

${ }^{1}$ Dosen Program Studi Pendidikan Elektronika, Fakultas Teknik, Universitas Negeri Jakarta. Jl. Rawamangun Muka Komplek Kampus UNJ, Jakarta 13220, Email: msoekardjo@unj.ac.id

2 Dosen Program Studi Pendidikan Informatika, Fakultas Teknik, Universitas Negeri Jakarta. Jl. Rawamangun Muka Komplek Kampus UNJ, Jakarta 13220,Email: lipurs@unj.ac.id 
melalui sertifikasi. Sertifikasi guru merupakan upaya peningkatan mutu guru yang dibarengi dengan peningkatan kesejahteraan guru, sehingga diharapkan dapat meningkatkan mutu pembelajaran dan mutu pendidikan di Indonesia secara berkelanjutan (Sunhaji, 2014).

Kenyataan di lapangan berdasarkan hasil penelitian (Syamsul, et al., 2017) mengatakan rata-rata kompetensi guru di Sulawesi Selatan masih berada di bawah standar pada tahun 20122013.

Apabila guru mengajar di șekolah hanya sekadar untuk menjalankan tugasnya sebagai suatu kewajiban, maka kegiatan pembelajaran akan dapat membosankan dan tidak mencapai hasil yang maksimal. Padahal kalau kita melihat definisi belajar adalah "learning is an enduring change in behavior, or in the capacity to behave in a given fashion, which result from practice or other formsof experience" (Schunk, 2012). Ini artinya guru yang telah lulus UKG harus dapat berubah, baik kognitif, sikap, dan keterampilan yang relatif menetap. Kenyataan ini tidak sejalan dengan yang dikemukakan (Gunarto, 2013) bahwa hasil survei Firma Person menunjukkan sistem pendidikan Indonesia terendah di dunia bersama Brasil dan Meksiko. Selanjutnya kajian Trends in International Mathematics and Science Study (TIMSS) 2012, di bidang matematik, Indonesia berada diurutan ke 38 dari 42 negara. Karena itu, guru diharapkan dapat melaksanakan tugasnya secara profesional. Namun fakta di lapangan menunjukkan bahwa sebagian guru belum memenuhi tuntutan peraturan perundangundangan yaitu bahwa seorang guru harus memiliki kualifikasi Pendidikan Sarjana (S) atau Diploma-Empat (D4) yang linear serta memiliki empat kompetensi yang memadai yaitu kepribadian, sosial, pedagogik dan profesional (Negara, 2008). Dalam Tabel 1 disajikan data guru yang belum memenuhi persyaratan kualifikasi pendidikan S1/D4.

\section{Tabel 1. Data Guru Berdasarkan Kualifikasi} Pendidikan

\begin{tabular}{c|c|c|c}
\hline \multirow{2}{*}{$\begin{array}{c}\text { Satuan } \\
\text { Pendidikan }\end{array}$} & \multirow{2}{*}{$\begin{array}{c}\text { Jumlah } \\
\text { Guru }\end{array}$} & \multicolumn{2}{|c}{$\begin{array}{c}\text { Kualifikasi } \\
\text { Pendidikan (\%) }\end{array}$} \\
\cline { 3 - 4 } & & $<\mathrm{S}$ & $>=\mathrm{S}$ \\
\hline SD & 1.648 .077 & 19,7 & 80,3 \\
\hline SMP & 644.399 & 13,2 & 86,8 \\
\hline SMA & 283.223 & 3,9 & 96,1 \\
\hline SMK & 260.694 & 7,8 & 97,2 \\
\hline Total & 1.836 .393 & 15,5 & 84,5 \\
\hline
\end{tabular}

Sumber: (Pendidikan, 2015)

Data pada Tabel 1 menunjukkan bahwa masih terdapat sekitar 15,5\% guru yang belum memenuhi tuntutan undang-undang bahwa seorang guru harus memiliki kualifikasi pendidikan (ijazah) S/D4 (Pendidikan, 2015). Selanjutnya dalam Tabel 2 disajikan data hasil UKG yang menunjukkan bahwa kompetensi guru khususnya kompetensi profesional dan pedagogik, masih belum memadai. Terlihat dari Tabel 2 bahwa nilai UKG dari tahun ke tahun terus meningkat namun hasilnya masih belum memuaskan.

Tabel 2. Perkembangan Nilai UKG 2012-2015

\begin{tabular}{r|c|c|c|c}
\hline \multirow{2}{*}{ Uraian } & \multicolumn{4}{|c}{ Tahun Pelaksanaan UKG } \\
\cline { 2 - 5 } & 2012 & 2013 & 2014 & 2015 \\
\hline Rerata Nilai & 45,85 & 47,84 & 48,95 & 56,77 \\
UKG & & & & \\
\hline
\end{tabular}

Sumber: (Kependidikan, 2015)

Dalam rangka pembinaan guru dan peningkatan profesional guru, pemerintah mengadakan Uji Kemampuan Guru (UKG). Target pertama UKG adalah melakukan pemetaan 
dalam rangka memperoleh baseline tentang kompetensi guru. Pada tahun 2015, terdapat 3.015.315 guru baik negeri maupun swasta yang mengikuti UKG di seluruh Indonesia. Guru-guru yang memiliki hasil UKG di atas standar minimal $(5,5)$ dinilai akan dapat memberikan pembelajaran dengan baik, melayani siswanya dengan baik sehingga siswa memiliki prestasi yang baik.

UKG pernah dilaksanakan pada tahun 2012 dengan jumlah mencapai 1,6 juta guru yang mengikutinya. Pada tahun 2012 tersebut, UKG dilakukan pada Tempat Uji Kompetensi (TUK) yang tersebar di seluruh pelosok tanah air dengan banyak sekali kendala yang ditemukan mulai dari lemahnya jaringan Internet dan fasilitas yang tersedia. Sejalan dengan hal di atas, (Juhadi, et al., Juni 2015) mengatakan tidak terdapat hububungan yang signifikan antara nilai UKG dengan nilai rata-rata UN mata pelajaran Geograpi di SMA kota Semarang.

Sementara pada UKG 2015 telah ditetapkan rerata yang diharapkan pemerintah yaitu 5,5 dan tidak berhubungan dengan pemberian tunjangan profesi. Hasil UKG 2015 akan digunakan untuk memperbaiki kualitas guru. Dari nilai yang dimiliki oleh masing-masing guru, maka Kemendikbud akan mempunyai suatu data dasar untuk memberikan pendidikan dan pelatihan (diklat) yang sesuai dengan kebutuhan atau kelemahan masing-masing guru. Diklat akan dibagi menjadi 10 grade berdasarkan nilai yang diperoleh guru. Setiap grade mencerminkan lamanya diklat dan kuantitas materi yang harus mereka kuasai agar kompetensi mereka menjadi lebih meningkat. Sebaliknya, jika guru dapat memiliki nilai yang bagus dan tinggi, tentunya
Kemendikbud akan memberikan reward yang sesuai.

Tabel 3. Jumlah Guru Berdasarkan Status Sertifikasi

\begin{tabular}{l|l|l|l|l}
\hline \multirow{2}{*}{$\begin{array}{l}\text { Status } \\
\text { Sertifikasi }\end{array}$} & \multicolumn{4}{|c}{ Jumlah Guru (\%) } \\
\cline { 2 - 5 } & $2009^{*}$ & $2011^{*}$ & $2012^{*}$ & $2015^{* *}$ \\
\hline Belum & 81,8 & 54,1 & 44,9 & 25,0 \\
\hline Sudah & 18,2 & 45,9 & 55,1 & 75,0 \\
\hline
\end{tabular}

Sumber: * (Kependidikan, 2015); ** (Pendidikan, 2015)

Tabel 3 menggambarkan perkembangan data guru yang sudah dan belum disertifikasi sejak tahun 2009 hingga 2015. Data ini bersumber dari survei ‘sertifikasi guru' program Better Education through Reformed Management and Universal Teacher Upgrading (BERMUTU) yang dilakukan Pusat Penelitian Kebijakan (Puslitjak) bekerja sama dengan Pusat Penilaian Pendidikan (Puspendik) dan Bank Dunia serta data tahun 2015 dari Direktorat Jenderal Guru dan Tenaga Kependidikan Kementerian Pendidikan dan Kebudayaan (Kependidikan, 2015).

Hasil UKG 2015 menunjukkan peta kekuatan dan kelemahan kompetensi guru dalam penguasaan pengetahuan. Peta kompetensi guru tersebut dikelompokkan menjadi 10 (sepuluh) kelompok kompetensi. Tindak lanjut pelaksanaan UKG diwujudkan dalam bentuk pelatihan guru paska UKG melalui program Guru Pembelajar. Tujuannya untuk meningkatkan kompetensi guru sebagai agen perubahan dan sumber belajar utama bagi peserta didik. Program Guru Pembelajar dilaksanakan melalui pola tatap muka, daring penuh (online), dan daring kombinasi (blended) tatap muka dengan online. Direncanakan pada akhir tahun 2019 mendatang, UKG akan dilaksanakan setiap tahun secara rutin untuk mencapai target rata-rata nilai hasil UKG 8,0. 
UKG 2015 menunjukkan beberapa poin penting tentang hasil yang diperoleh sbb: 1) Hasil UKG 2015 cukup memprihatinkan karena mayoritas guru Indonesia masih mempunyai skor UKG yang lebih rendah dibanding standar minimal yang ditetapkan untuk tahun 2015 yaitu 55 yang merupakan angka SKM (Standar Kompetensi Minimal). Standar kompetensi minimal ini akan terus dinaikkan secara bertahap setiap tahunnya sehingga nantinya diharapkan menunjukkan peningkatan pula dari sisi kompetensi guru secara nyata di lapangan; 2) Sebanyak 305 kabupaten/kota (59\%) yang berlokasi di luar Pulau Jawa menunjukkan skor UKG di bawah standar minimal 55. Ini tentu menunjukkan bahwa masih ada kesenjangan kemajuan sektor pendidikan antara Pulau Jawa dengan daerah atau pulau-pulau lainnya di Indonesia. Secara berurutan skor UKG dari yang tertinggi hingga tersendah berdasarkan pulaupulau besar di Indonesia adalah: Jawa, Sumatera, Kalimantan, Sulawesi, Nusa Tenggara, Maluku dan Papua; 3) Ternyata, secara statistik tidak ada perbedaan yang nyata antara skor UKG guru-guru yang berada di wilayah perkotaan (kotamadya) dengan wilayah yang lebih jauh dari pusat pemerintahan daerah (kabupaten); 4) Guru-guru yang berusia 41 tahun lebih mempunyai kecendrungan skor UKG yang menurun. Makin berumur sang guru, makin rendah skor UKG yang diperolehnya; 5) Pada kenyataannya, nilai UKG guru PNS sekolah negeri lebih rendah dibanding guru-guru sekolah swasta; 6) Cukup menggembirakan bahwa guru-guru bersertifikasi mempunyai skor UKG lebih baik dibanding guruguru yang belum memiliki sertifikat pendidik, baik untuk PNS, GTY, GTT, maupun Honor
Daerah (Honda); 7) Guru-guru dengan kualifikasi pendidikan lebih tinggi mempunyai skor UKG lebih baik dibanding guru-guru dengan kualifikasi pendidikan yang lebih rendah.

Dengan memerhatikan kesimpulan di atas, tentunya guru harus peduli dan berupaya meningkatkan skor UKG karena ini adalah salah satu cara untuk menilai kinerja guru, dan berhubungan erat dengan kompetensi yang dimiliki serta kaitannya dengan sertifikasi guru (salah satunya berupa tunjangan profesi). Hal ini seharusnya dapat memberikan motivasi bagi guru agar tetap untuk berprstasi dalam mengajar. Dengan demikian akan terbangun hubungan emosional seorang guru dengan anak siswanya. Membangun emosi guru dengan siswa tidak bisa dianggap sepele, karena emosi seoang guru dapat mempengaruhi proses kognitif dan strategi, emosi juga dapat mempengaruhi keputusan, dan emosi juga dapat mempengarui motivasi, dan pengatuh tersebut bias timbal balik (Spector, et al., 2014). Oleh karena itu guru harus selalu mengembangkan diri agar menjadi semakin profesional dan memiliki kompetensi yang baik, meliputi kompetensi profesional, akademik, sosial, dan kepribadian.

Kajian terdahulu tentang perbandingan kompetensi guru yang sudah dan belum disertifikasi menunjukkan adanya kecenderungan bahwa guru yang telah disertifikasi dengan yang belum disertifikasi kompetensinya tidak jauh berbeda. Penelitian tentang "Dampak Kebijakan Sertifikasi Terhadap Kinerja Guru di Daerah Riau" yang dilakukan (Suarman, et al., 2014) di tiga kabupaten yakni Pelalawan, Kampar dan Rokan Hulu di Provinsi Riau ditemukan bahwa dari segi kemampuan pedagogik, guru yang sudah 
disertifikasi, kemampuan pedagogiknya sebagai guru tidak berbeda secara statistik dengan guru yang belum disertifikasi. Hal ini sejalan dengan hasil penelitian lain yang dikemukakan (Sili Sabon, 2017) dikatakan bahwa tidak terdapat perbedaan komptensi yang signifikan antara guru yang sudah dan belum mengikuti UKG. Artinya cara guru mengajar maupun persiapan dalam pelaksanaan proses belajar mengajar (PBM) belum berbeda secara nyata.

Ditinjau dari sisi kemampuan profesional temuannya juga sama. Kinerja guru yang sudah disertifikasi dan yang belum disertifikasi menunjukkan tidak ada perbedaan. Indikator kemampuan profesional yang dinilai adalah penguasaan materi, struktur, konsep dan pola pikir keilmuan yang mendukung mata pelajaran yang diampu.

(Brotosedjati, 2012) juga melakukan penelitian serupa yang dilakukan di 35 kabupaten/kota di Jawa Tengah dengan jumlah responden sebanyak 1.540 orang yang berasal dari 20 jenis sekolah mulai dari TK/RA sampai SMA/SMK negeri maupun swasta. Hasil kajiannya menunjukkan sertifikasi telah dapat meningkatkan kesejahteraan, martabat guru, kedisiplinan dan kompetensi pedagogis guru, namun sertifikasi tidak banyak mengubah kinerja seorang guru karena baik guru yang telah disertifikasi maupun yang belum disertifikasi sama-sama konsisten melakukan perubahan ke arah yang lebih baik dengan atau tanpa adanya sertifikasi.

Hasil temuan kajian (Nasir, et al., 2013) mengungkapkan bahwa dari segi kemampuan pedagogik, kinerja guru Biologi yang sudah disertifikasi lebih baik daripada yang belum disertifikasi. Perbedaan ini secara statistik signifikan. Namun demikian dari segi kemampuan profesional kinerja guru Biologi yang sudah disertifikasi tidak berbeda dari yang belum disertifikasi.

Hasil kajian terdahulu dengan topik-topik yang serupa ini yaitu membandingkan kinerja atau kompetensi pedagogik dan profesional antara guru yang sudah dan belum disertifikasi menunjukkan temuan yang kurang lebih sama yaitu bahwa tidak terdapat perbedaan kinerja yang berarti antara guru yang sudah dan belum disertifikasi. Kajian Suarman \& Syahza (2014) menyimpulkan secara khusus bahwa kompetensi pedagogik dan profesional guru tidak berbeda antara guru yang sudah dan belum disertifikasi.

Hasil kajian (Nasir, et al., 2013) dan (Brotosedjati, 2012) memang memberikan hasil yang sedikit berbeda khususnya terkait kompetensi pedagogik yaitu bahwa kompetensi pedagogik guru yang sudah disertifikasi lebih baik daripada yang belum disertifikasi, namun itu semua dapat dipahami karena guru yang sudah mengikuti pelatihan untuk mendapat sertifikat pendidik tentunya mendapat pengetahuan baru tentang metode pembelajaran yang baru yang dapat diterapkannya di dalam kelas sehingga membuatnya berbeda dari guru yang belum disertifikasi. Lebih lanjut, kajian khusus oleh Nasir dkk. (2013) sangatlah kasuistis yaitu dilakukan hanya untuk guru Biologi saja kemudian lingkupnya pun sangat mikro yaitu di tingkat gugus atau rayon saja, sehingga hasilnya dapat berbeda dengan kajian lainnya yang lingkupnya lebih makro. Beberapa Hasil kajian tersebut jika dikaitkan dengan nilai UKG 2015 yang diutarakan sebelumnya, memperlihatkan 
bahwa hasilnya kurang lebih sama yaitu bahwa nilai kompetensi pedagogik dan profesional guru yang sudah dan belum disertifikasi kurang lebih sama.

Sejak tahun 2015, UN tidak lagi menjadi standar kelulusan. Kelulusan siswa ditentukan sepenuhnya oleh sekolah. PP Nomor 19 tahun 2005 jo PP Nomor 32 tahun 2013 yang mengatur hal ini direvisi. Meski demikian, keberadaannya masih dianggap penting oleh sekolah. Tujuan UN sepenuhnya untuk menilai pencapaian standar kompetensi lulusan pada mata pelajaran tertentu secara nasional. Dan hasilnya digunakan untuk pemetaan mutu, dasar seleksi masuk jenjang pendidikan selanjutnya, dan pembinaan. Sebagai alat pemetaan nasional, UN dapat dipakai untuk mengukur kinerja sekolah, anak-anak didik serta para guru. Jadi, UN tetap menjadi patokan untuk mengetahui kemampuan anak didik dan sekolah. Melalui peringkat UN tersebut dapat menjadi cerminan untuk melihat posisi sekolah di antara sekolah lainnya. Hasil UN lainnya yang juga penting, di antaranya untuk melakukan pembinaan sekolah dan guru, perencanaan peningkatan mutu pendidikan di suatu wilayah, dan sebagai salah satu instrumen seleksi masuk ke jenjang yang lebih tinggi, termasuk perguruan tinggi di luar negeri. Dari sisi peserta didik, UN merupakan hak untuk dapat mengetahui capaian kompetensinya setelah menjalani proses pembelajaran dalam kurun waktu tertentu.

UN yang dilakukan serempak di seluruh Indonesia sementara ini masih dipakai sebagai "tolok ukur" keberhasilan sekolah dalam bidang kognitif di suatu provinsi. Berdasarkan hail UN, kemampuan sekolah diklasifikasikan ke dalam empat kategori, yaitu:

\section{Tabel 4. Klasifikasi Sekolah Berdasarkan} Nilai UN

\begin{tabular}{c|c|l}
\hline Nilai & Status & \multicolumn{1}{c}{ Keterangan } \\
\hline A & $\begin{array}{c}\text { Sangat } \\
\text { Baik }\end{array}$ & $\begin{array}{l}\text { Nilai UN lebih dari 85,0 } \\
\text { dan kurang dari atau sama } \\
\text { dengan 100; } \\
\text { Nilai UN lebih dari 70,0 } \\
\text { dan kurang dari atau sama } \\
\text { dengan 85,0; } \\
\text { Nilai UN lebih dari 55,0 } \\
\text { dan kurang dari atau sama } \\
\text { dengan 70,0; } \\
\text { Nilai UN kurang dari atau } \\
\text { sama dengan 55,0. }\end{array}$ \\
\hline
\end{tabular}

Klasifikasi sekolah berdasarkan hasil UN pada Tabel 4 di atas penting untuk mengukur ketercapaian kompetensi yang pada akhirnya digunakan sebagai acuan untuk pengembangan standar isi, standar proses, standar penilaian pendidikan, standar pendidik dan tenaga kependidikan secara nasional.

Berdasarkan hasil penelitian dan pembahasan (Juhadi, et al., Juni 2015), maka dapat diambil kesimpulan sebagai berikut: (1) Nilai UKG mata pelajaran Geografi tahun 2012 di Kota Semarang memiliki hasil yang bervariasi. Dari 37 Sekolah diperoleh data, tidak ada Sekolah yang masuk ke dalam klasifikasi Amat Baik, 3\% atau 1 Sekolah masuk kedalam klasifikasi Baik, 35\% atau 13 Sekolah masuk ke dalam klasifikasi Cukup, 38\% atau 14 Sekolah masuk ke dalam klasifikasi Sedang dan 24\% atau 9 Sekolah masuk ke dalam klasifikasi Kurang. (2) Nilai UN mata pelajaran Geografi tahun 2013 di SMA se Kota Semarang dengan Guru sekaligus peserta Uji Kompetensi memiliki hasil yang bervariasi. Dari 37 Sekolah diperoleh data, 84\% atau 31 Sekolah dalam klasifikasi Baik, $16 \%$ atau 6 sekolah dalam klasifikasi Sedang dan tidak ada Sekolah masuk dalam klasifikasi Baik Sekali, Kurang dan Kurang 
Sekali. (3) Berdasarkan kriteria penerimaan hipotesis, maka Ha ditolak karena $-0.354<=$ 0.325. Dapat disimpulkan dalam penelitian ini bahwa tidak ada hubungan positif yang signifikan antara nilai UKG dengan nilai rata-rata UN mata pelajaran Geografi Tahun 2013 di SMA se Kota Semarang.

Kedua hal tersebut, menimbulkan pertanyaan apakah prestasi anak dalam UN dikarenakan guru-guru di sekolah sangat baik dalam mengajar? Apakah guru-guru di sekolah tersebut berpengalaman dalam mengajar sehingga siswa memperoleh nilai UN yang tinggi? Apakah nilai yang diperoleh siswa dalam UN karena proses pembelajaran di sekolah yang cukup baik? Apakah hasil UN tersebut ada hubungan dengan kemampuan UKG guru? Kita sadari bersama bahwa untuk mengukur kualitas pendidikan banyak faktor yang turut mempengaruhinya. Faktor-faktor tersebut di antaranya adalah (1) guru, (siswa), (3) lingkungan, (4) orang tua dan lain sebagainya. Semua pertanyaan tersebut perlu di analisis dan dicari tahu penyebab keberhasilan siswa memperoleh nilai UN yang tinggi.

\section{METODOLOGI PENELITIAN}

Penelitian ini merupakan penelitian deskriptif kuantitatif dengan pendekatan korelasional. Penelitian ini dilaksanakan mulai bulan Februari sampai dengan November 2017. Pengumpulan data dilakukan secara non-interaktif melalui dokumen tertulis maupun elektronik. Data yang digunakan dalam penelitian ini adalah data sekunder.

Data pertama yang digunakan berupa rata-rata nilai UN SMA/SMK/MA tahun 2016 baik negeri maupun swasta. Data tersebut bersumber dari Pusat Penilaian Pendidikan, Badan Penelitian dan Pengembangan, Kemendikbud. Data yang terkumpul dapat disajikan per wilayah baik secara nasional, provinsi, kota/kabupaten, maupun sekolah. Filter diterapkan untuk mata pelajaran Matematika di DIY. Data kedua yang digunakan adalah rata-rata nilai UKG tahun 2015 per sekolah yang ada di DIY. Data tersebut berasal dari Pusat Data dan Statistik Pendidikan (PDSP), Kemendikbud. Filter terhadap data UKG diterapkan untuk guru Matematika di DIY.

Populasi dalam penelitian ini adalah seluruh guru Matematika yang mengikuti UKG tahun 2015 di DIY dan seluruh siswa SMA kelas 12 yang mengikuti UN tahun 2016 di DIY. Sampel yang digunakan adalah sampel jenuh, karena semua data guru mata pelajaran Matematika di sekolah yang mengikuti UKG tahun 2015 di DIY digunakan, demikian pula dengan data semua siswa disekolah tersebut yang mengikuti UN tahun 2016 di DIY. Analisis atas data yang diperoleh dilakukan menggunakan rumus regresi dan korelasi.

\section{HASIL DAN PEMBAHASAN}

Hasil pelaksanaan UKG 2015 untuk DIY, dapat dikemukakn bahwa Nilai tertinggi UKG diperoleh di Kabupaten Sleman dan Kotamadya Yogyakarta. Nilai terendah UKG terdapat di Kabupaten Kulon Progo. Di kabupaten ini sekaligus banyak terdapat nilai UKG yang rendah. Rerata nilai UKG tertinggi banyak dijumpai di Kabupaten Sleman.

Selengkapnya nilai pelaksanaan UKG tahun 2015 untuk provinsi DI Yogyakarta ditampilkan pada tabel berikut: 
Tabel 5. Nilai UKG DIY Tahun 2015

\begin{tabular}{|c|c|c|c|}
\hline $\begin{array}{l}\text { Kabupaten/ } \\
\text { Kota }\end{array}$ & $\begin{array}{c}\text { Nilai } \\
\text { Tertinggi }\end{array}$ & $\begin{array}{c}\text { Nilai } \\
\text { Terendah }\end{array}$ & $\begin{array}{l}\text { Nilai } \\
\text { Rerata }\end{array}$ \\
\hline \multirow{2}{*}{$\begin{array}{l}\text { Kabupaten } \\
\text { Sleman }\end{array}$} & 94,4 & 44,4 & 70,1 \\
\hline & $\begin{array}{l}\text { SMA Muh. } \\
\text { Mlati }\end{array}$ & $\begin{array}{c}\text { SMA } \\
\text { Sunan } \\
\text { Kalijogo }\end{array}$ & \\
\hline \multirow{2}{*}{$\begin{array}{l}\text { Kabupaten } \\
\text { Gunung } \\
\text { Kidul }\end{array}$} & 8,44 & 42,6 & 66,87 \\
\hline & $\begin{array}{l}\text { SMAN } 2 \\
\text { Wonosari }\end{array}$ & $\begin{array}{l}\text { SMA IKIP } \\
\text { Veteran } \\
\text { Ponjong }\end{array}$ & \\
\hline \multirow{2}{*}{$\begin{array}{l}\text { Kabupaten } \\
\text { Bantul }\end{array}$} & 88,89 & 50,93 & 72,65 \\
\hline & $\begin{array}{l}\text { SMAN } 17 \\
\text { Bantul }\end{array}$ & $\begin{array}{l}\text { SMA Muh. } \\
\text { Imogiri }\end{array}$ & \\
\hline \multirow{2}{*}{$\begin{array}{l}\text { Kabupaten } \\
\text { Kulon } \\
\text { Progo }\end{array}$} & 78,52 & 42,6 & 64,8 \\
\hline & $\begin{array}{l}\text { SMAN } 1 \\
\text { Wates }\end{array}$ & $\begin{array}{c}\text { SMA } \\
\text { BOPKRI } \\
\text { Wates }\end{array}$ & \\
\hline \multirow{2}{*}{$\begin{array}{l}\text { Kotamadya } \\
\text { Yogyakarta }\end{array}$} & 94,4 & 31,49 & 68,24 \\
\hline & $\begin{array}{c}\text { SMAN } 7 \\
\text { Yogyakarta }\end{array}$ & $\begin{array}{c}\text { SMA } \\
\text { Gadjah } \\
\text { Mada }\end{array}$ & \\
\hline
\end{tabular}

UKG tahun 2015 ini hanya diikuti oleh $74,5 \%$ dari semua sekolah yang ada di Kabupaten Bantul. Nilai tertinggi sebesar 88,89 diperoleh di SMAN 17 Bantul. Nilai terendah sebesar 50,93 terdapat di SMA Muhammadiyah Imogiri. Nilai rerata untuk Kabupaten Bantul sebesar 72,65 (diatas nilai minimal).

UKG tahun 2015 ini hanya diikuti oleh $61,3 \%$ dari semua sekolah yang ada di Kabupaten Gunung Kidul. Nilai tertinggi sebesar 88,44 diperoleh di SMAN 2 Wonosari. Nilai terendah sebesar 42,59 terdapat di SMA IKIP Veteran Ponjong. Nilai rerata untuk Kabupaten Gunung Kidul sebesar 66,87 (di atas nilai minimal).

UKG tahun 2015 ini hanya diikuti oleh $65 \%$ dari semua sekolah yang ada di Kabupaten Kulon Progo. Nilai tertinggi sebesar 78,52 diperoleh di SMAN 1 Wates. Nilai terendah sebesar 42,59 terdapat di SMA BOPKRI Wates.
Nilai rerata untuk Kabupaten Kulon Progo sebesar 64,80 (diatas nilai minimal).

UKG tahun 2015 ini hanya diikuti oleh 65,6\% dari semua sekolah yang ada di Kabupaten Sleman. Nilai tertinggi sebesar 94,44 diperoleh di SMA Muhammadiyah Mlati. Nilai terendah sebesar 44,44 terdapat di SMA Sunan Kalijogo. Nilai rerata untuk Kabupaten Sleman sebesar 70,05 (diatas nilai minimal).

UKG tahun 2015 ini hanya diikuti oleh 73,5\% dari semua sekolah yang ada di Kotamadya Yogyakarta. Nilai tertinggi sebesar 94,44 diperoleh di SMAN 7 Yogyakarta. Nilai terendah sebesar 31,48 terdapat di SMA Gadjah Mada. Nilai rerata untuk Kotamadya Yogyakarta sebesar 68,26 (diatas nilai minimal).

\section{Korelasi Hasil UN 2015 - 2016 dan UKG 2015 Mata Pelajaran Matematika Kabupaten Bantul}

Gambar berikut adalah deskripsi data dan hasil perhitungan koeefisen korelasi dan regresi dengan menggunakan software SPSS. Secara berturut-turut deskripsi analisis data pada koefisien korelasi adalah sebagai berikut:

\begin{tabular}{|c|c|c|c|}
\hline \multicolumn{4}{|c|}{ Correlations } \\
\hline & & Y5 & X5 \\
\hline \multirow[t]{2}{*}{ Pearson Correlation } & Y5 & 1.000 & .352 \\
\hline & X5 & .352 & 1.000 \\
\hline \multirow[t]{2}{*}{ Sig. (1-tailed) } & Y5 & & .019 \\
\hline & X5 & .019 & \\
\hline \multirow[t]{2}{*}{$\mathrm{N}$} & Y5 & 35 & 35 \\
\hline & X5 & 35 & 35 \\
\hline
\end{tabular}

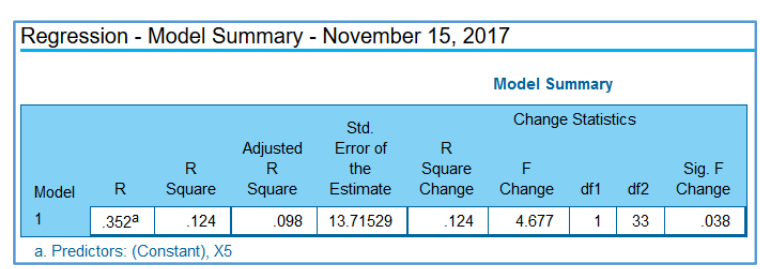




\begin{tabular}{|c|c|c|c|c|c|c|}
\hline \multicolumn{7}{|c|}{ Regression - ANOVA - November 15, 2017} \\
\hline & & \multicolumn{5}{|c|}{ ANOVA $^{a}$} \\
\hline \multicolumn{2}{|c|}{ Model } & $\begin{array}{l}\text { Sum of } \\
\text { Squares }\end{array}$ & df & $\begin{array}{l}\text { Mean } \\
\text { Square }\end{array}$ & $\mathrm{F}$ & Sig. \\
\hline \multirow[t]{3}{*}{1} & Regression & 879.871 & 1 & 879.871 & 4.677 & $.038^{b}$ \\
\hline & Residual & 6207.599 & 33 & 188.109 & & \\
\hline & Total & 7087.470 & 34 & & & \\
\hline \multicolumn{7}{|c|}{ a. Dependent Variable: Y5 } \\
\hline \multicolumn{7}{|c|}{ b. Predictors: (Constant), X5 } \\
\hline
\end{tabular}

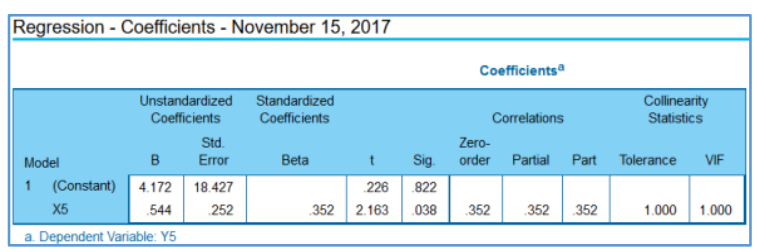

Gambar 1. Persamaan regresi: $\hat{\mathbf{Y}}=\mathbf{4 , 1 7 2}+0,352$ $\mathrm{X}_{1}$ untuk olah data Kabupaten Bantul

Persamaan regresi di atas signifikan. Hal ini dapat diketahui dari $F_{\text {hitung }}>F_{\text {tabel, }}$ yaitu $F_{\text {hitung }}$ $=4,667>\mathrm{F}_{\text {tabel }}=4,14$. maka dapat disimpulkan bahwa koefisien arah regresi $\mathrm{Y}$ atas $\mathrm{X}_{1}$ "signifikan". Kekuatan hubungan antara variabel $\mathrm{X}_{1}$ dengan $\mathrm{Y}$ ditunjukkan oleh koefisien korelasi product moment sebesar $\mathrm{r}_{\mathrm{y} 1}=0,352$ dan uji keberartian koefisien korelasi dengan uji t didapat harga $t_{\text {hitung }}=2,163$ Harga $t_{\text {tabel }}$ dengan $\mathrm{dk}=34$ dan taraf signifikan $\alpha=0,05$ didapat nilai table sebesar 2,042. Karena $\mathrm{t}_{\text {hitung }}=2,163<\mathrm{t}_{\text {tabel }}=2,042$ dapat disimpulkan bahwa tidak terdapat hubungan positif antara hasil UKG dengan dengan hasil UN.

Hasil perhitungan koefisien determinasi $\mathrm{R}^{2}=0,124$, ini artinya hanya $12,4 \%$ nilai $\mathrm{UN}$ ditentukan oleh nilai UKG.

\section{Korelasi Hasil UN 2015 - 2016 dan UKG 2015 Mata Pelajaran Matematika Kabupaten Gunung Kidul}

Gambar berikut adalah deskripsi data dan hasil perhitungan koefisien korelasi dan regresi dengan menggunakan software SPSS.
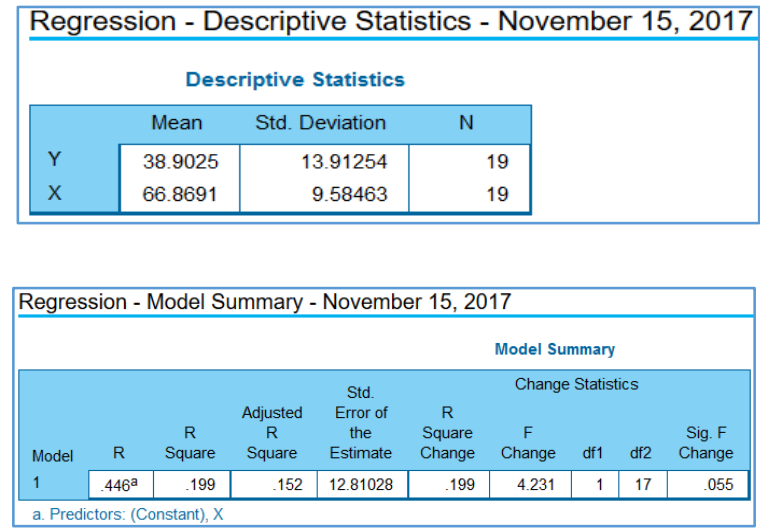

\begin{tabular}{|c|c|c|c|c|c|c|}
\hline \multicolumn{7}{|c|}{ Regression - ANOVA - November 15, 2017} \\
\hline & & & \multicolumn{4}{|c|}{ ANOVA $^{a}$} \\
\hline \multicolumn{2}{|c|}{ Model } & $\begin{array}{l}\text { Sum of } \\
\text { Squares }\end{array}$ & df & $\begin{array}{l}\text { Mean } \\
\text { Square }\end{array}$ & $\mathrm{F}$ & Sig. \\
\hline \multirow[t]{3}{*}{1} & Regression & 694.301 & 1 & 694.301 & 4.231 & $.055^{\mathrm{b}}$ \\
\hline & Residual & 2789.755 & 17 & 164.103 & & \\
\hline & Total & 3484.056 & 18 & & & \\
\hline \multicolumn{7}{|c|}{ a. Dependent Variable: $Y$} \\
\hline \multicolumn{7}{|c|}{ b. Predictors: (Constant), $\mathrm{X}$} \\
\hline
\end{tabular}

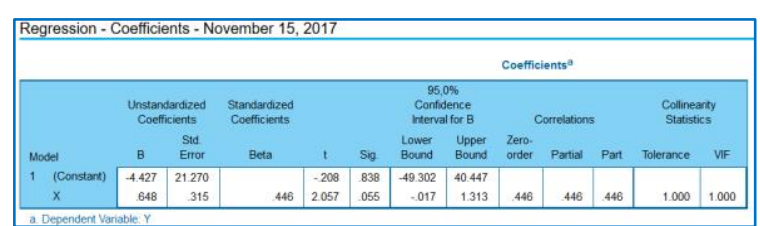

Gambar 2. Persamaan regresi: $\hat{\mathbf{Y}}=-\mathbf{4 , 4 2 7}+\mathbf{0 , 6 4 6}$ $\mathrm{X}_{1}$ untuk olah data Kabupaten Gunung Kidul

Persamaan regresi di atas signifikan. Hal ini dapat diketahui dari $F_{\text {hitung }}>F_{\text {tabel}}$, yaitu $F_{\text {hitung }}$ $=4,231>\mathrm{F}_{\text {tabel }}=4,14$. maka dapat disimpulkan bahwa koefisien arah regresi $\mathrm{Y}$ atas $\mathrm{X}_{1}$ "signifikan". Kekuatan hubungan antara variabel $\mathrm{X}_{1}$ dengan $\mathrm{Y}$ ditunjukkan oleh koefisien korelasi product moment sebesar $\mathrm{r}_{\mathrm{y} 1}=0,446$ dan uji keberartian koefisien korelasi dengan ujit $\mathrm{t}$ didapat harga $t_{\text {hitung }}=2,067$ Harga $t_{\text {tabel }}$ dengan $d k$ $=34$ dan taraf signifikan $\alpha=0,05$ didapat nilai $t_{\text {table }}$ sebesar 2,042. Karena $t_{\text {hitung }}=2,067>t_{\text {tabel }}=$ 2,042 dapat disimpulkan bahwa terdapat hubungan positif antara hasil UKG dengan dengan hasil UN. 
Hasil perhitungan koefisien determinasi $\mathrm{R}^{2}=0,152$, ini artinya hanya $15,2 \%$ nilai $\mathrm{UN}$ ditentukan oleh nilai UKG.

\section{Korelasi Hasil UN 2015 - 2016 dan UKG 2015 Mata Pelajaran Matematika Kabupaten Sleman}

Gambar berikut adalah deskripsi data dan hasil perhitungan koeefisen korelasi dan regresi dengan menggunakan software SPSS.

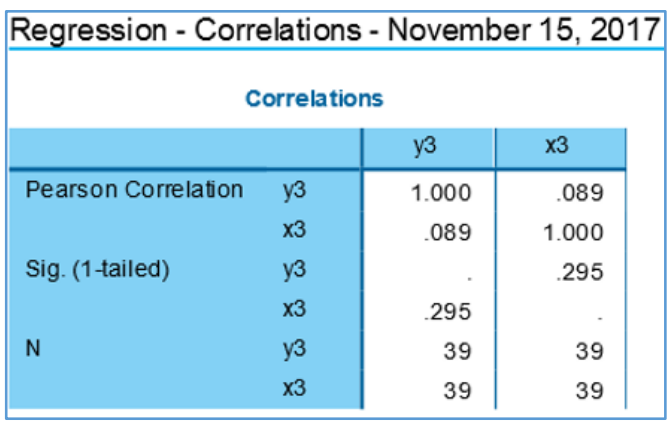
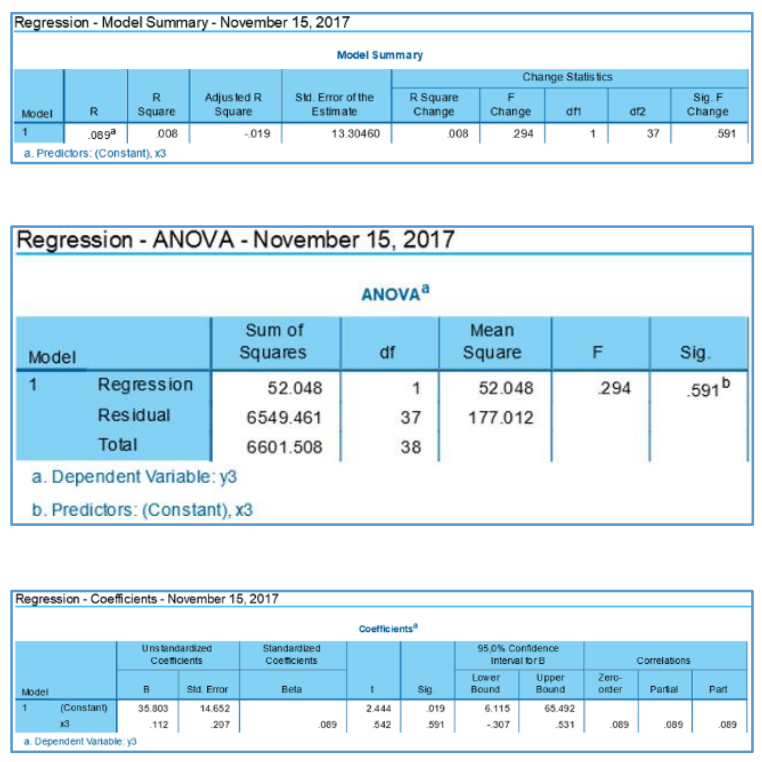

Gambar 3. Persamaan regresi: $Y=35,08+0,089$ $\mathrm{X}_{1}$ untuk olah data Kabupaten Gunung Kidul.

Persamaan regresi di atas tidak signifikan. Hal ini dapat diketahui dari $\mathrm{F}_{\text {hitung }}<$ $\mathrm{F}_{\text {tabel}}$, yaitu $\mathrm{F}_{\text {hitung }}=0,294<\mathrm{F}_{\text {tabel }}=4,07$. maka dapat disimpulkan bahwa koefisien arah regresi $\mathrm{Y}$ atas $\mathrm{X}_{1}$ “tidak signifikan”.
Kekuatan hubungan antara variabel $\mathrm{X}_{1}$ dengan Y ditunjukkan oleh koefisien korelasi product moment sebesar $\mathrm{r}_{\mathrm{y} 1}=0,08$ dan uji keberartian koefisien korelasi dengan ujit $t$ didapat harga $t_{\text {hitung }}=2,444$ Harga $t_{\text {tabel }}$ dengan $\mathrm{dk}$ $=38$ dan taraf signifikan $\alpha=0,05$ didapat nilai $\mathrm{t}_{\text {table }}$ sebesar 2,42. Karena $\mathrm{t}_{\text {hitung }}=2,44>\mathrm{t}_{\text {tabel }}=$ 2,042 dapat disimpulkan bahwa terdapat hubungan positif antara hasil UKG dengan dengan hasil UN. Hasil perhitungan koefisien determinasi $\mathrm{R}^{2}=0,089$ ini artinya hanya $8 \%$ nilai UN ditentukan oleh nilai UKG.

\section{Korelasi Hasil UN 2015 - 2016 dan UKG 2015 Mata Pelajaran Matematika Kota Yogyakarta}

Gambar berikut adalah deskripsi data dan hasil perhitungan koeefisen korelasi dan regresi dengan menggunakan software SPSS.

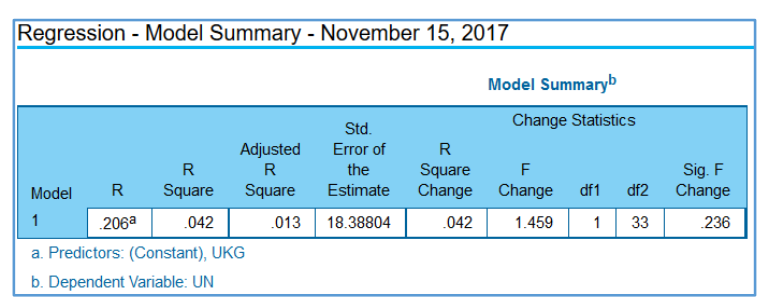

\begin{tabular}{|c|c|c|c|c|c|c|}
\hline \multicolumn{7}{|c|}{ Regression - ANOVA - November 15, 2017} \\
\hline \multicolumn{7}{|c|}{ ANOVA $^{a}$} \\
\hline \multicolumn{2}{|c|}{ Model } & $\begin{array}{l}\text { Sum of } \\
\text { Squares }\end{array}$ & df & $\begin{array}{l}\text { Mean } \\
\text { Square }\end{array}$ & $\mathrm{F}$ & Sig. \\
\hline \multirow[t]{3}{*}{1} & Regression & 493.373 & 1 & 493.373 & 1.459 & $.236^{b}$ \\
\hline & Residual & 11157.962 & 33 & 338.120 & & \\
\hline & Total & 11651.335 & 34 & & & \\
\hline \multicolumn{7}{|c|}{ a. Dependent Variable: UN } \\
\hline \multicolumn{7}{|c|}{ b. Predictors: (Constant), UKG } \\
\hline
\end{tabular}

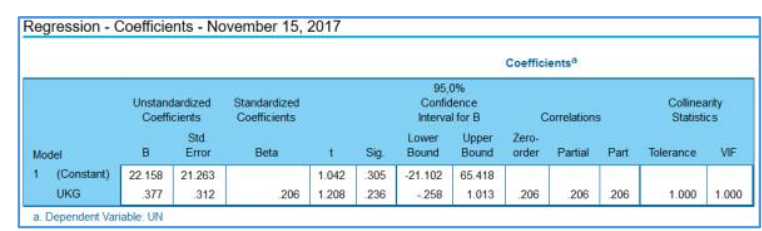

Gambar 4. Persamaan regresi: $Y=22,158+0,206$ $\mathrm{X}_{1}$ untuk olah data Kabupaten Kulon Progo. 
Persamaan regresi di atas signifikan. Hal ini dapat diketahui dari $\mathrm{F}_{\text {hitung }}<\mathrm{F}_{\text {tabel }}$, yaitu $\mathrm{F}_{\text {hitung }}$ $=1,459<\mathrm{F}_{\text {tabel }}=4,14$. maka dapat disimpulkan bahwa koefisien arah regresi $\mathrm{Y}$ atas $\mathrm{X}_{1}$ "tidak signifikan”. Kekuatan hubungan antara variabel $\mathrm{X}_{1}$ dengan $\mathrm{Y}$ ditunjukkan oleh koefisien korelasi product moment sebesar $\mathrm{r}_{\mathrm{y} 1}=0,06$ dan uji keberartian koefisien korelasi dengan ujit $t$ didapat harga $t_{\text {hitung }}=1,028$ Harga $t_{\text {tabel }}$ dengan $d k$ $=33$ dan taraf signifikan $\alpha=0,05$ didapat nilai $\mathrm{t}_{\text {table }}$ sebesar 2,034. Karena $\mathrm{t}_{\text {hitung }}=1,028<\mathrm{t}_{\text {tabel }}=$ 2,042 dapat disimpulkan bahwa tidak terdapat hubungan positif antara hasil UKG dengan dengan hasil UN. Hasil perhitungan koefisien determinasi $\mathrm{R}^{2}=0,013$ ini artinya hanya $1,3 \%$ nilai UN ditentukan oleh nilai UKG.

\section{Rekapitulasi Korelasi UKG Terhadap UN DIY}

Nilai rerata UKG per kabupaten yang tinggi tidak sebanding dengan rerata nilai $\mathrm{UN}$ yang tinggi. Rerata UKG di Kabupaten Bantul tidak menyebabkan rerata UN di kabupaten tersebut paling tinggi untuk DIY. Demikian pula, rerata UN per kabupaten yang tertinggi (Kabupaten Gunung Kidul) tidak berbanding lurus dengan rerata UKG di kabupaten tersebut yang berada nomor 3. Sedangkan dari perhitungan koefisien determinasi $\mathrm{R}^{2}=0,098$, berarti hanya 9,8\% nilai UN ditentukan oleh nilai UKG atau dapat dikatakan bahwa nilai UKG tidak mempengaruhi perolehan nilai UN.

Tabel 6. Rekap Perhitungan Korelasi UKG Terhadap UN DIY

\begin{tabular}{|c|c|c|c|c|c|c|c|}
\hline \multirow[b]{2}{*}{ Kabupaten/Kota } & \multicolumn{3}{|c|}{ UKG } & \multirow[b]{2}{*}{ Korelasi } & \multicolumn{3}{|c|}{ UN } \\
\hline & $\begin{array}{c}\text { Nilai } \\
\text { Tertinggi }\end{array}$ & Nilai Terendah & $\begin{array}{l}\text { Nilai } \\
\text { Rerata }\end{array}$ & & $\begin{array}{c}\text { Nilai } \\
\text { Tertinggi }\end{array}$ & $\begin{array}{c}\text { Nilai } \\
\text { Terendah }\end{array}$ & $\begin{array}{l}\text { Nilai } \\
\text { Rerata }\end{array}$ \\
\hline & 94,4 & 44,4 & & & & & \\
\hline $\begin{array}{c}\text { Kabupaten } \\
\text { Sleman }\end{array}$ & $\begin{array}{l}\text { SMA Muh. } \\
\text { Mlati }\end{array}$ & $\begin{array}{c}\text { SMA Sunan } \\
\text { Kalijogo }\end{array}$ & 70,1 & $0,8 \%$ & 76,25 & 19,38 & 42,43 \\
\hline Kobungten & 8,44 & 42,6 & & & & & \\
\hline Gunung Kidul & $\begin{array}{l}\text { SMAN } 2 \\
\text { Wonosari }\end{array}$ & $\begin{array}{l}\text { SMA IKIP Veteran } \\
\text { Ponjong }\end{array}$ & 66,87 & $19,9 \%$ & 82,26 & 23,29 & 37,85 \\
\hline $\begin{array}{c}\text { Kabupaten } \\
\text { Bantul }\end{array}$ & $\begin{array}{c}88,89 \\
\text { SMAN } 17 \\
\text { Bantul }\end{array}$ & $\begin{array}{c}50,93 \\
\text { SMA Muh. Imogiri }\end{array}$ & 72,65 & $12,4 \%$ & 80,83 & 20,0 & 41,62 \\
\hline $\begin{array}{l}\text { Kabupaten } \\
\text { Kulon Progo }\end{array}$ & $\begin{array}{l}78,52 \\
\text { SMAN } 1 \\
\text { Wates }\end{array}$ & $\begin{array}{c}42,6 \\
\text { SMA BOPKRI } \\
\text { Wates }\end{array}$ & 64,8 & $25,6 \%$ & 74,39 & 21,11 & 38,45 \\
\hline $\begin{array}{l}\text { Kotamadya } \\
\text { Yogyakarta }\end{array}$ & $\begin{array}{c}94,4 \\
\text { SMAN } 7 \\
\text { Yogyakarta }\end{array}$ & $\begin{array}{c}31,49 \\
\text { sMA Gadjah Mada }\end{array}$ & 68,24 & $1,3 \%$ & 81,58 & 20,68 & 46,8 \\
\hline
\end{tabular}

Korelasi Hasil UN 2015 - 2016 dan UKG 2015 Mata Pelajaran Matematika Provinsi DI Yogyakarta

Untuk tujuan menentukan bentuk dan makna korelasi antara UKG 2015 dengan hasil UN 2015 di DIY, maka hanya sekolah-sekolah yang memiliki data UKG 2015 dan sekaligus melaksanakan UN 2016 yang dapat dianalisis. Analisis data SPSS untuk seluruh kabupaten/kota di DIY. Deskripsi data ditampilkan secara berturut-turut dalam gambar berikut: 

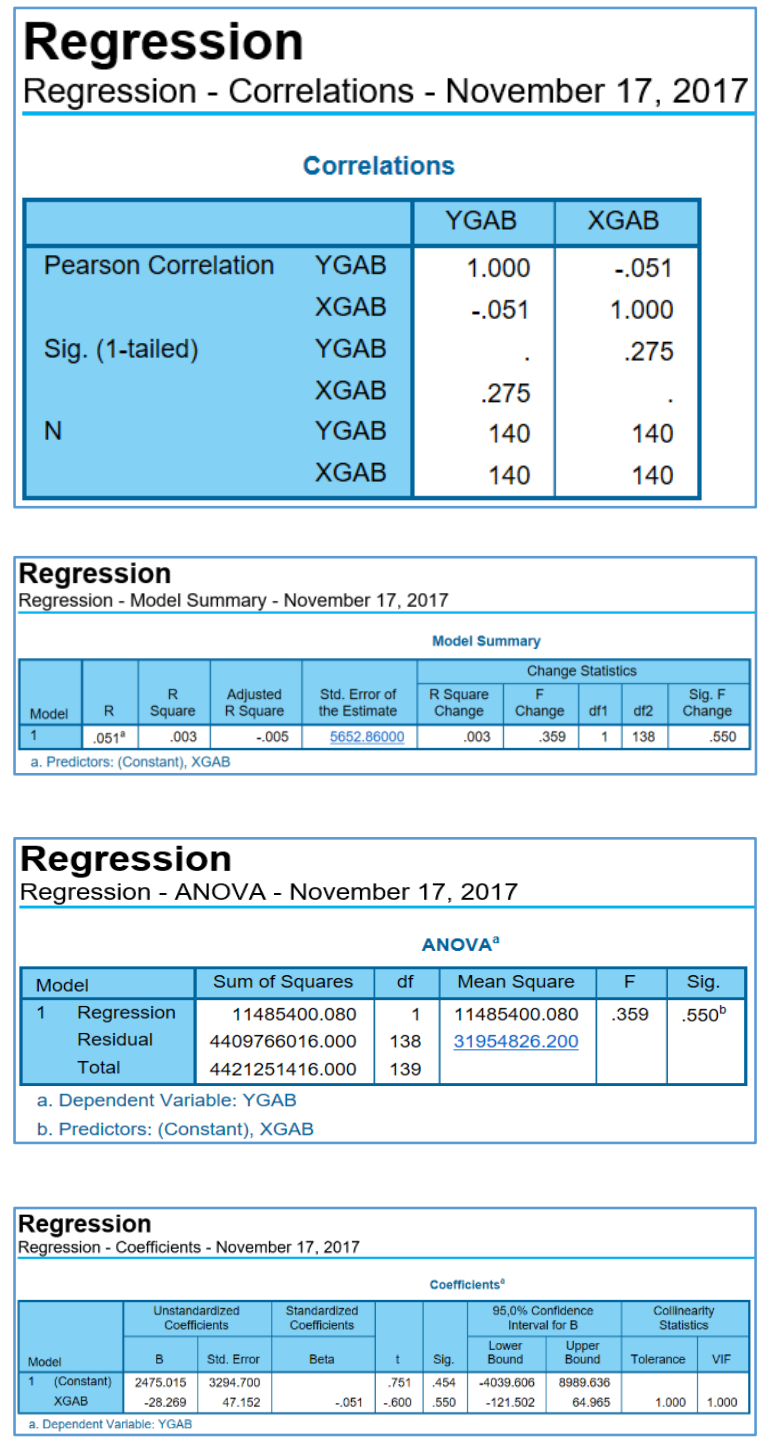

Gambar 6. Data gabungan persamaan regresi dari data SPSS adalah Y $=2475,015-0,051 X_{1}$

Persamaan regresi di atas tidak signifkan. Hal ini dapat diketahui apabila $F_{\text {hitung }}<\mathrm{F}_{\text {tabel. }}$. Dari data di atas diperoleh Fhitung $=0,539<\mathrm{F}_{\text {tabel }} 3,44$ sehingga arah regresi sangat tidak signifikan. Dari perhitungan koefisien regresi dengan SPSS, diperoleh koefisien korelasi $r_{\mathrm{y} 1}=0,506$ dan dari $\mathrm{db} 38$ diperoleh $\mathrm{t}_{\text {tabel }} 1,98$. Karena $\mathrm{t}_{\text {hitung }}=-0,6,<$ $\mathrm{t}_{\text {tabel }}=1.98$ maka dapat dikatakan koefisien korelasi juga tidak signifikan. Oleh dapat dikatakan bahwa tidak terdapat hubungan yang signifikan antara nilai UKG dengan nilai UN. Namun demikian apabila, perhitungan koefisien determinasi $R^{2}=0,003$, berarti hanya $0,03 \%$ nilai UN ditentukan oleh nilai UKG atau dapat dikatakan bahwa nilai UKG tidak mempengaruhi perolehan nilai $\mathrm{UN}$.

Korelasi antara UKG 2015 dengan hasil UN 2015 di tiap kabupaten di DIY diperlakukan serupa dan hasilnya dapat dilihat pada tabel $7 \mathrm{di}$ bawah ini.

\section{Tabel 7. Signifikansi UKG 2015 terhadap UN 2016 per Kabupaten di DIY}

\begin{tabular}{lc}
\hline Kabupaten/Kota & $\begin{array}{c}\text { Kontribusi } \\
\text { UKG terhadap }\end{array}$ \\
& UN \\
\hline Kabupaten bantul & $12,4 \%$ \\
Kabupaten Gunung Kidul & $15,2 \%$ \\
Kabupaten Sleman & $8 \%$ \\
Kabupaten Kulon Progo & $1,3 \%$ \\
Kotamadya Yogyakarta & $0,3 \%$ \\
\hline
\end{tabular}

\section{KESIMPULAN}

Merujuk pada dua analisis data, analisis tabel dan analisis regresi, maka di DIY nilai UKG Matematika 2015 tidak mempengaruhi perolehan nilai UN Matematika 2016. Hanya 0,03\% nilai UN Matematika 2016 yang ditentukan oleh nilai UKG Matematika 2015. Meskipun tidak seluruh guru Matematika di DIY mengikuti UKG tahun 2015, namun dari hasil yang sudah ada terlihat bahwa UKG Matematika yang telah dilaksanakan pada tahun 2015 belum memiliki dampak terhadap peningkatan UN Matematika pada tahun 2016.

\section{DAFTAR PUSTAKA}

Brotosedjati S. Kinerja Guru Yang telah Lulus Sertifikasi Guru Dalam Jabatan [Jurnal] // Jurnal Manajemen Pendidikan Universitas Veteran Bangun Nusantara Sukoharjo. - 2012. - 2 : Vol. I. hal. 189199. 
Direktorat Jenderal Guru dan Tenaga Kependidikan. Data Uji Kompetensi Guru 2012-2015 [Buku]. - Jakarta : Kementerian Pendidikan dan Kebudayaan, 2015.

Gunarto, Teacher's Competence Examination (UKG) [Jurnal] // Magistra. - 2013. - hal. 87-98.

Hakim A. Analisis Gambaran Kompetensi Guru Terhadap Prestasi Belajar Siswa SMP Pada Ujian Nasional Tahun 2015 Provinsi Daerah Istimewa Yogyakarta [Laporan]. - Jakarta: Pusat Data dan Statistik Pendidikan dan Kebudayaan, 2016.

Juhadi Murtadho dan Budi Santoso Apik, Hubungan Antara Nilai Uji Kompetensi Guru (UKG) Dengan Nilai Rata-Rata Ujian Nasional Mata Pelajaran Geografi Tahun 2013 Di SMA Se Kota Semarang [Jurnal]. - Semarang: Edu Geography, Universitas Negeri Semarang, Juni 2015. - 7 : Vol. III. - 63-68.

Kementerian Pendidikan dan Kebudayaan. Peraturan Menteri Pendidikan dan Kebudayaan (Permendikbud) no. 57 tahun 2012 tentang Uji Kompetensi Guru (UKG) [Buku]. - Jakarta : Kementerian Pendidikan dan Kebudayaan, 2012.

Kementerian Pendidikan dan Kebudayaan. Permendikbud Nomor 57 tahun 2012 tentang Uji Kompetensi Guru [Buku]. Jakarta: Kementerian Pendidikan dan Kebudayaan, 2012.

Kementerian Sekretaris Negara Peraturan Pemerintah Nomor 74 Tahun 2008 tentang Guru [Buku]. - Jakarta : Kementerian Sekretaris Negara, 2008.
Nasir M., Samingan dan Abdullah, Komparatif Kinerja Guru Biologi Yang Belum Sertifikasi Dengan Guru Biologi Yang Sudah Sertifikasi Pada SMA Negeri Rayon 01 Kabupaten Pidie [Jurnal]// Jurnal Biologi Edukasi Universitas Syiah Kuala Banda Aceh. - 2013. - 2 : Vol. V. hal. 60-65.

Pusat Data dan Statistik Pendidikan. Persekolahan 2015 [Laporan]. - Jakarta : Sekretariat Jenderal Kementerian Pendidikan dan Kebudayaan, 2015.

Sardiman A. Interaksi dan Motivasi Belajar Mengajar [Buku]. - Jakarta: Rajawali Pers, 1987.

Schunk Dale H. Learning Theories: an Education Perspective [Buku]. - Boston: Pearson, 2012.

Sili Sabon Simon. Persepsi Siswa Terhadap Kompetensi Guru Yang Sudah dan Belum Disertifikasi [Jurnal] // Jurnal Pendidikan dan Kebudayaan. - 2017. - hal. 55-80.

Spector dan et.al Handbook of Research on Educational Communications and Technolgy 4th edition [Buku]. - New York : Springer, 2014.

Suarman dan Syahza A. Dampak Kebijakan Sertifikasi Terhadap Kinerja Guru di Daerah Riau [Jurnal] // Jurnal Pendidikan Lembaga Penelitian Universitas Riau Pekanbaru. - 2014. - 2 : Vol. IV. - hal. 7283. 